\title{
Supply Chain Integration: Does Organizational Culture Matter?
}

\author{
Mary G. Porter \\ School of Leadership and Organizational Design, \\ University of Phoenix, 3104 Greenwood Lane, St. Charles, Il 60175 \\ Email: mporter@emergentsafety.com
}

\begin{abstract}
The purpose of this quantitative correlational study was to identify relationships between organizational culture types, supply chain integration, and firm performance. The study process included obtaining data from 201 supply chain professionals and procurement specialists working in various companies throughout the United States. Supply chain integration data and firm performance derived from results obtained from participants completing a 5-point Likert-type scale survey. The Organizational Culture Assessment Instrument was used to determine organizational culture types. Results indicated a significant correlation between supply chain integration and firm performance. All three integration variables, customer, supplier, and internal were significantly and positively correlated with total integration and firm performance. Results also indicated that supply chain integration increased when organizational flexibility was present. Unexpectedly, both clan and adhocracy cultures were significantly correlated to supply chain integration and firm performance. The results from this study added to literature and provided supply chain managers practical knowledge of the significant influence organizational culture can have on supply chain integration performance. Results of this study substantiate that a flexible organizational structure, as shown in the clan and adhocracy cultures, increases supply chain integration and firm performance. As competitive forces intensify, the need for firms to develop a flexible organizational structure to leverage supply chain integration practices will increase. The results of this research could provide organizational leaders more insights into increasing supply chain integration efforts and improved firm performance through flexible culture alignment.
\end{abstract}

Keywords: supply chain integration, supply chain management, organizational culture, relational theory, firm performance

\section{INTRODUCTION}

The hypercompetitive and dynamic 2016 market environment revealed the need for change in organizational processes. Rapidly changing business environments presented a multitude of uncertainties for organizational leaders to sustain a competitive advantage on their own, prompting leaders to look beyond traditional boundaries (Sambasivan \& Yen, 2010). Over the last decade, supplychain scholars noted supply chain integration (SCI) was a key factor in achieving organizational improvements and creating sustainable competitive advantage (Cao et al., 2015). Supply chain integration helped organizational leaders realign internal and external resources to consolidate their supply chain improving long-term performance (Huo et al., 2014). Consequently, business partnerships and collaboration capabilities became critical for integration improvement.

Various researchers have recognized that organizational culture had a significant influence on operational performance (Cadden et al., 2013). Leaders supporting a culture orientation viewed the supply chain as a whole rather than a set of fragmented parts. A holistic approach created customer value and increased performance through a synchronized flow of intra-and inter-firm activities (Mello \& Stank, 2005; Mentzer et al., 2001). Whitfield and Landeros (2006) suggested cultural consistency and cultural understanding within the supply chain added to successful supply chain strategies.

The theoretical foundation for the study was embedded in relational theory, whereby supply chain partners collaborate in developing long-term relationships and combined resources to improve firm performance and competitive advantage. Supply chain integration depends on partnerships that exhibit compatible behaviors of trust, knowledge sharing, transparency, and joint coordination efforts (Cadden et al., 2013). Theorists of the relational view noted that increased interaction between supply chain members-built trust and relationship linkages critical to supply chain integration (Johnson et al., 2014). However, few studies existed about the relationships between SCI and organizational culture.

In recent years, SCI gained importance among practitioners and academics (Braunscheidel et al., 2010; Flynn et al., 2010; Kim \& Lee, 2010). Despite the importance of SCI in supply chain literature confirming the positive impact of SCI on organizations' performance, there remained a problem of inconsistencies related to definitions and dimensions. Recently, researchers reported mixed results of studies pertaining to SCI and firm performance (Cao et al., 2015; Huo et al., 2014).

The general problem was the lack of consistent research findings and the limited empirical evidence in SCI literature, which made it difficult for supply chain leaders to design and implement practical integration solutions. Leaders recognized that inter-firm business processes and integration initiatives required organizational alignment to minimize overall costs and maximize firm performance (Braunscheidel et al., 2010; Cao et al., 2015). Organizational alignment necessitated major changes in organizational culture and mind-set among supply chain members (Braunscheidel et al., 2010; Cao et al., 2015). The specific problem was how to identify organizational culture 
types that were most applicable for supply chain integration initiatives and increased firm performance. Braunscheidel $e t$ al. (2010) noted a scarcity of research pertaining to organizational culture, SCI, and firm performance.

Most studies on SCI identified firm performance as a key indicator of integration success; therefore, conduction of the study involved using firm performance measures and hypotheses to answer the first research question:

- $\quad$ Research Question 1. To what extent, if any, does supply chain integration correlate to firm performance?

The following research question was designed to investigate the relationship between organizational culture and supply chain integration, as measured by firm performance. Based on the four culture types and three dimensions of supply chain integration: internal, customer, and supplier, it was hypothesized that organizational culture may either reinforce or hinder the effectiveness of SCI efforts that affect firm performance.

- Research Question 2. To what extent, if any, does organizational culture correlate to the relationship between supply chain integration and firm performance?

The answers to the above two questions provided a better understanding of the relationship dynamics between organizational culture types and SCI which could help reduce barriers impeding firm performance. New knowledge gained could benefit managers and procurement specialists within the supply chain which may lead to enhanced relationships, process improvements, communication channels, and increases in competitive advantage. Supply chain channel partners may benefit from the study results and lead to higher levels of collaboration. Specifically, a culture that has a flexible organizational structure and an external focus may be more effective than cultures that have inflexible organizational structures and/or have an internal focus.

\section{LITERATURE REVIEW}

Over the last 3 decades, firms restructured and reengineered processes to increase organizational performance and improve customer satisfaction (Fawcett \& Magnan, 2002). In the midst of this pursuit for excellence, executives recognized their lack of competencies and resources to achieve organizational success in a turbulent and fast paced environment. This, along with current trends including globalization, outsourcing, increased customer technology knowledge, shorter product life cycles, and high stakeholder expectations forced organizations to expand beyond traditional boundaries. These trends have been the catalyst of increased interest in supply chain integration as a means of breaking down organizational functional silos and the monolithic business model.

Supply chain integration was considered to be of strategic and operational importance in the supply chain management process (Leuschner et al., 2013; Mentzer et al., 2001). Supply chain integration originated from a system perspective that asserts the entire supply chain working together performs better than segregated firm activities.
Harrigan (1984) further argued that the old paradigm of vertical integration whereby an organization owns $100 \%$ of all operations to gain competitive advantage is outdated. In a tapered-integration strategy by Harrigan (1984), organizations do not own $100 \%$ of adjacent businesses but gained similar benefits by relying on other firms to provide a portion of their services and activities.

\subsection{Theoretical Background}

Prior to the mid-1980s, the emphasis on governing supply chain relationships was to protect against opportunistic behavior through arm's length relationships (Patnayakuni et al., 2006). This practice began to change in the late 1990s as supply chain relationships were marked by increased collaboration among trading partners. Organizations leading this cooperative behavior between trading partners were Walmart, Lucent Technology, Cisco, and Sara Lee (Patnayakuni et al., 2006). It is argued that the flow of information and knowledge sharing among trading partners is embedded in the firm's relational competency, including culture, policies, systems, and individual employees. To accomplish transparent communication, firms had to move from adversarial relationships to collaborative ones.

Participation, communication, and trust are key relational competencies that influence supply chain cooperation and performance. Developing relational capabilities between organizations is a gradual process to improve firm performance and competitive position in the marketplace (Delbufalo, 2012). The consequence of frequent interaction and relationship development among firms leads to shared values, inter-organizational teams, knowledge transfer, and exchange of information.

The gradual new process of developing relational rents with another organization depends on a culture that embraces teamwork, information sharing, risk-taking, and relational skills. Adaptable culture related skills play an important role in SCI (Cao et al., 2015). Relationship capabilities that build trust and confidence between trading partner interactions are a by-product of organizational culture. When organizational culture alignment is absent, firms may not achieve integration objectives and performance improvements (Cao et al., 2015).

Organizational culture represents a pattern of shared beliefs and values that guide firm behavior (Cadden et al., 2013). Culture also reflected the ways of organizational member thinking, openness, and transparency that are critical in establishing supply chain relationships. The relational theory maintained that in an exchange situation between supply chain partners, organizational culture types supporting knowledge sharing, flexibility, joint collaboration, and reciprocal relationship development increased competitive advantage and firm success (Braunscheidel et al., 2010; Sambasivan \& Yen, 2010).

Theoretical perspectives such as resource-based, knowledge-based and strategy structure contributed greatly to the understanding of supply chain management. However, these theories overlooked SCI complexities and the importance of organizational culture in building relational rents to sustain competitive firm performance. The relational view provided a theoretical backdrop best suited for conducting this study. 


\subsection{Supply Chain Integration}

Since the early 1980s, supply chain management became a prominent study of research among organizational theorists (Christopher, 1982). The term supply chain management was first used to describe the logistics between internal and external organizational functions to manage the flow of materials and information across organizational boundaries (Ellram \& Cooper, 2014). Scholars and practitioners disagreed upon a solid definition of supply chain management as they realized it was a complex web of networks, relationships, and processes moving upstream and downstream to provide products and services to customers (Ellram \& Cooper, 2014). Supply chain integration was frequently mentioned as the key characteristic of supply chain management (Wang et al., 2018).

The shift of autonomous organizations acting alone to an integrated supply chain of knowledge sharing and collaboration among multiple organizations was a complex transformation. Varied SCI concepts and definitions added to implementation barriers. Moving from SCI theory to SCI practice was difficult for most organizations as there was not a defined set of definitions, dimensions, and integration succession plans. The results of research conducted by Childerhouse and Towill (2011) indicated organizations with strong internal integration including efficient processes, lean production, sharing of information, and operations planning are able to easier integrate upstream with suppliers. Customer integration is more difficult to achieve, as it required collaborative planning, joint coordination efforts regarding inventory forecasting, and open transparent information sharing. In order to decrease integration barriers, organizations needed to improve internal integration first, followed by upstream integration with suppliers, and finally downstream integration with customers (Childerhouse \& Towill, 2011).

Supply chain scholars have classified integration into many definitions including strategic, internal and external, downstream, and knowledge (Mellat-Parast, 2013). While some studies characterized SCI by internal and external integration, a common view was to split external integration into customer and supplier. Therefore, many researchers consolidated the multiple SCI definitions into three dimensions; internal integration within a firm, downstream integration with the customer, and upstream integration with the supplier (Danese \& Ramano, 2011; Kim, 2013).

\subsubsection{Internal Integration}

Internal integration referred to a firm's ability to reduce functional silos, establish cross-functional teams, share information and knowledge across departmental boundaries, and standardize processes (Kim, 2013). Isolated use of internal capabilities eroded the possibility of creating a seamless value chain where teams worked together across organizational boundaries (Kim \& Lee, 2010; Kim, 2013). Internal integration capabilities affected the degree of customer and supplier integration and were identified as the foundation of SCI (Kim, 2013; Zhao et al., 2011).

Firms that incorporated a high level of internal integration were more successful in external collaboration, knowledge sharing, and joint problem-solving activities (Feng et al., 2013). Furthermore, enhanced internal integration led to a greater understanding of customer and supplier needs and opportunities. A strong internal environment that embraced cross-fertilization of ideas and knowledge is better able to collaborate in new product development efforts.

\subsubsection{Supplier Integration}

Previous studies defined supplier integration as the collaboration and sharing of operational, financial, and strategic knowledge between a buying firm and its suppliers (Narasimhan et al., 2010). Relational ties-built knowledge sharing, flexible practices, and capabilities to adapt to an uncertain environment. Inter-organizational relationships in supplier integration can range from "arms-length," shortterm obligations, and contract-driven to cooperative, trustbased, and long-term alliances (Vijayasarathy, 2010). Interorganizational relationships can either hinder or positively influence supply integration.

\subsubsection{Customer Integration}

Customer integration is referred to as the most important competency for achieving high-level firm performance (Closs \& Savitskie, 2003). Customer integration depended on the intimacy of relationships and information shared between the focal firm and the end customer. Customer collaboration improved an organization's ability to link customers within the supply chain effectively (Udin et al., 2008). Barratt (2004) suggested information exchange and collaboration based on relationships needed to be implemented at all levels within an organization including tactical and strategic. Operational integration coupled with the tactical integration of marketing, promotions, and new product introductions increased customer performance levels.

Supply chain integration received considerable attention in recent years. Numerous theories sought to understand the underlying criteria for supply chain success and reasons for failure (Fawcett et al., 2008). A common theme throughout SCI literature was supply chains are more likely to succeed when they adapt, align, and integrate internal, customer, and supplier information and processes. Overall empirical evidence supported the positive impact of integration practices on firm performance, however, varied findings are common (Leuschner et al., 2013). The wide array of SCI definitions, dimensions, constructs, and inconsistent measurements was an implementation challenge. Therefore, the first study hypothesis states:

H1. Supply chain integration, represented as internal, supplier, and customer is positively related to firm performance.

\subsection{Organization Culture and Supply Chain Integration}

Supply chain integration was recognized as an integral factor in optimizing firm performance and competitive advantage. Integration efforts involved cultural changes that aligned trading partner organizations. This cultural alignment improved customer service levels and firm performance (Braunscheidel et al., 2010). The shift from functional silos to inter-firm integration required a major shift in organizational culture and mindset across the supply chain (Braunscheidel et al., 2010). Thus, in the era of supply 
chain vs supply chain, firms needed to address issues concerning organizational culture types and which ones were most appropriate for SCI success.

Supply chain integration was not easy to implement, as it required relation-specific investments among supply chain partners and a shift away from adversarial interactions to collaborative partnerships (Cao et al., 2015). Organizational culture has been defined as the assumptions, values, and beliefs shared among organizational members (Huo, 2012). Cultural compatibility among supply chain partners was an important factor in supply chain integration efforts. Firms that shared similar cultural attributes increased communication efforts, trust, and reciprocal knowledge exchange.

The competing values framework (CVF) developed by Quinn and Rohrbaugh (1983) was used to determine an organization's primary cultural orientation. The underlying behaviors associated with organizational culture are represented in the four quadrants of the CVF. The framework explains how different cultural values and norms influence organizational members and their propensity toward SCI efforts. The first dimension is the flexibility and control axis, which represents the competing demands of change and stability (Hartnell, et al, 2011; Tong \& Arvey, 2015). The second dimension is the internal and external focus axis that reflects the competing demands of organizational focus (Hartnell et al., 2011; Tong \& Arvey, 2015).

The intersection of the axes creates the four culture types that are contradictory or competing on the diagonal (Cameron \& Quinn, 2011), as shown in Figure 1. The clan culture represents flexible structure and internal focus while the opposite quadrant represents a market culture with a controlled structure and external focus. Conversely the adhocracy culture represents a flexible structure with an external focus while the hierarchy culture represents a controlled structure with an internal focus. Based on the four culture types (adhocracy, clan, market, and hierarchy) and three dimensions of supply chain integration (internal, customer, and supplier) it was hypothesized that an adhocracy culture had a greater degree of positive correlation on SCI efforts than clan, market, or hierarchy culture types. This leads to the following hypotheses:

H2.1. Adhocracy culture type with greater organizational flexibility will have a greater degree of positive correlation on supply chain integration than hierarchy and market culture types identified as low organizational flexibility.

H2.2. Adhocracy culture type with an external focus will have a greater degree of positive correlation on supply chain integration than hierarchy and clan culture types identified as having an internal focus.

A firm's cultural characteristics determined the integration efforts with supply chain partners. Huo et al. (2014) suggested firms that pursued a transactional cost strategy emphasize process efficiency, formalized rules, structured workplaces, and organizational stability. Hierarchical culture is best suited in stable and unchanging market environments where functional silos promote specialization and efficiency (Cao et al., 2015). Firms with this type of culture had difficulty adapting to change and volatile market conditions. Brunscheidel et al. (2010) found that hierarchy cultures negatively influenced both internal and external integration.

Internally focused cultures with stringent practices and procedures tend to stay within organizational boundaries and are less responsive to external integration. However, outward focused cultures that viewed suppliers and customers as partners rather than separate supply chain entities increased customer delivery performance (Braunscheidel et al., 2010). Culture was a key factor in understanding why some organizations fail during integration efforts while others succeed (Cao et al., 2015).

\section{METHODOLOGY}

\subsection{Data Collection Methodology and Method}

Empirical inconsistencies found in extant literature relating to SCI dimensions, performance outcomes, and definitions indicate the complexity and multifaceted attributes of supply chain management. Most of the reviewed literature suggests that SCI is generally beneficial. However, contradictions and variations in SCI dimensions are evident among studies (Flynn et al., 2010; Schoenherr \& Swink, 2012). Given SCI complexities and inconsistent research outcomes, a systematic and quantitative approach to the research study provided generalizable findings for supply chain practitioners. When empirical results were inconsistent, as in supply chain integration, a systematic evaluation of specific variables and scientific measurements helped to define logical and practical SCI solutions.

A quantitative, correlational design was used to investigate the relationships between SCI and organizational culture. A correlational research design expressed numerical relationships between the independent variables (supply chain integration and organizational culture) and the dependent variable (firm performance). The correlational design consisted of measuring variables and determining the degree of a relationship between SCI and organizational culture.

This study investigated the effects of organizational characteristics and types that were strongly associated with improved supply chain integration performance. Based on the four culture types (adhocracy, clan, market, and hierarchy) and three dimensions of supply chain integration (internal, customer, and supplier) it was hypothesized that an adhocracy culture had a greater degree of positive influence on SCI efforts than clan, market, or hierarchy culture types. Supply chain integration and increased firm performance was significantly influenced by an organization's prevailing culture type.

The research adopted a non-experimental method design through the use of a 5-point Likert scale to measure SCI and a forced-ranking scale to measure organizational culture types. This web-based survey was sent to supply chain professionals and procurement specialists throughout the U.S. The research data was gathered using a random sampling of participants regarding SCI practices and organizational culture characteristics.

\subsection{Instrumentation}

The internal scale to measure supply chain integration followed Braunscheidel's et al. (2010) study. The scale was 
divided into three sections based on the independent variables: internal, customer, and supplier integration. Participants evaluated the extent of integration using a 5point Likert-type Scale ranging from 1=strongly agree to $5=$ strongly disagree. The firm performance scale for the study was adapted from Chen et al., (2007). Participants were asked to evaluate their firm's relative performance compared with competitors using a 5-point Likert-type Scale.

The forced-choice scale, also known as forced ranking, was adapted from the study by Cameron and Quinn (2011). The psychometric diagnostic tool categorized the culture orientation of organizations by assessing the six dimensions of organizational culture (Cameron \& Quinn, 2011). The competing values framework (CVF) as shown in Figure 1 was the foundation for developing the Organizational Culture Assessment Instrument (OCAI) (Cameron \& Quinn, 2011.

The OCAI evaluated the characteristics of four culture types: clan, adhocracy, hierarchy, and market to create culture profiles founded on values, assumptions, and interpretations of the organization's cultural environment (Cameron \& Quinn, 2011). Examining these cultural dimensions provided insight into the underlying culture of the organization.

The survey was previously verified for reliability and validity through literature reviews, pre-tests, and study outcomes. The correlation of independent and dependent variables was appropriately measured using a 5-point Likert- type scale and the OCAI. Coefficient alpha also known as Cronbach's alpha measured the internal consistency of survey questions. Cronbach's alpha scales .70 and higher indicated that all scales were reliable.

\subsection{Data Collection}

The study population consisted of 840 supply chain individuals and procurement specialists working within various United States industries. These supply chain professionals performed functions embedded in a network of trading partner relationships and were chosen based on their knowledge of supply chain management and logistics. This knowledge spanned a number of strategic and tactical business functions within a particular firm and across businesses. The actual selection of survey participants was based on a simple random sampling.

Empirical data was collected through a web-based survey and accessible via the internet 24/7. The survey was administered through SurveyMonkey which provided greater flexibility for participants to answer questions. Respondent surveys containing errors were removed from the study leaving the sample size at $\mathrm{N}=201$.

The largest group of participants worked within the manufacturing industry $(20.9 \%)$ with either the second highest being the distribution $(7.0 \%)$ or energy and utilities $(7.0 \%)$ industry. The most common cultures were clan $(29.9 \%)$ or market $(28.9 \%)$.

\section{Flexibility}

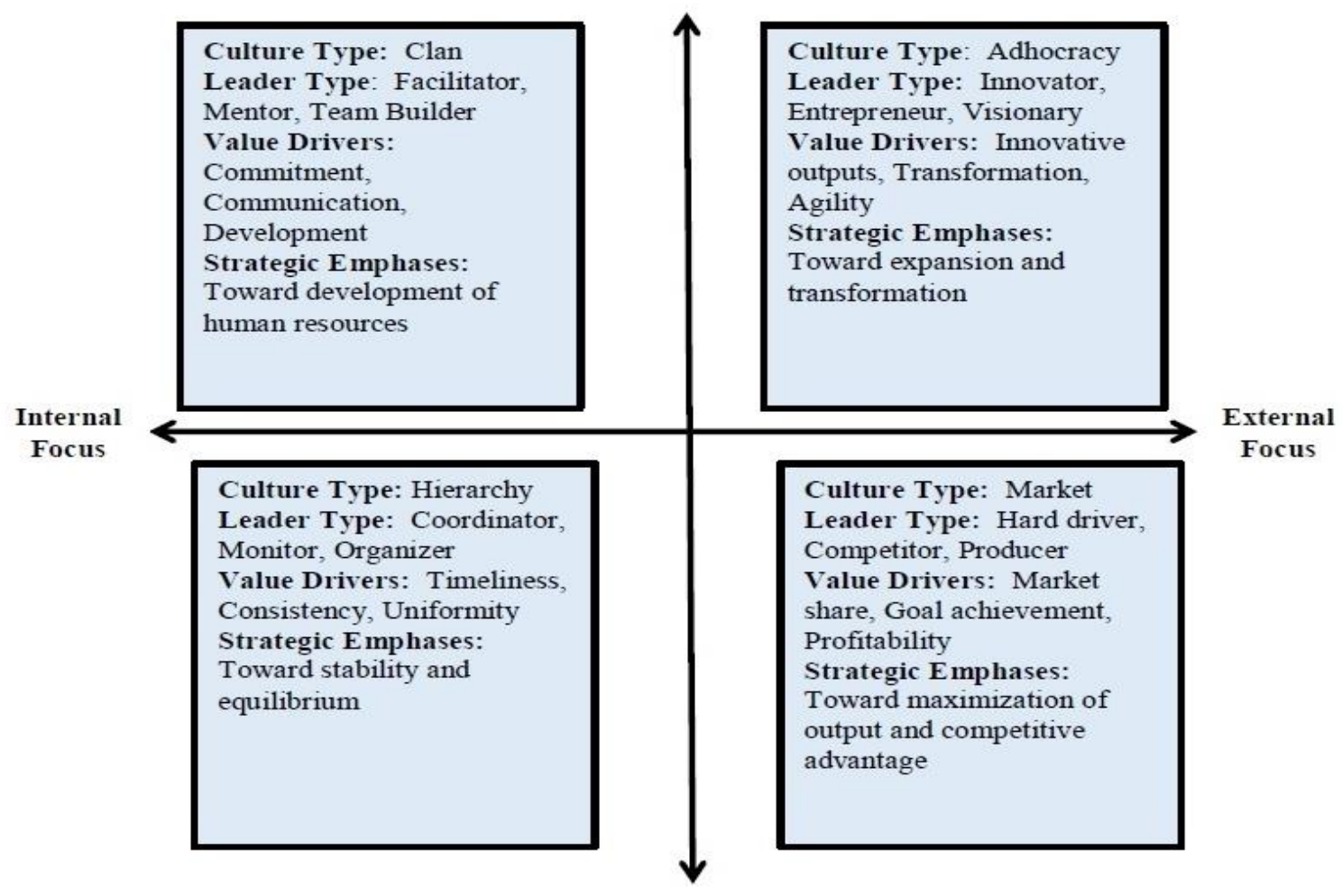

\section{Control}

Figure 1 Competing Values Framework as defined by Cameron and Quinn, 2011 


\subsection{Data Analysis}

The raw data collected from SurveyMonkey was transferred from Excel to SPSS Statistics software for analysis. The statistical software, SPSS, was the foundation for data analysis, data interpretation, generating reports, and creating graphs. Supply chain integration scores were calculated at the individual level notably customer integration, supplier integration, and internal integration and aggregated at the total integration level. Categorical scores using forced ranking were collected to determine the organizational culture type.

Average scores were calculated and distributed on a scatterplot. Pearson statistics determined the strength of bivariate relationships between variables. Regression models were developed, and linear regression analysis was performed to determine a positive or negative correlation between variables. The objective of correlational data analysis was to describe the degree of association between variables. The significance of the degree of association determined whether to reject or fail to reject the study hypotheses.

Data analysis involved creating multiple regression models that analyzed the relationship between variables. A regression model was used to analyze the associated changes between the covariate variable (organizational culture) and the independent variables of SCI (internal, customer, and supplier). The covariate variable represented all four cultural types independently such that clan, adhocracy, market, and hierarchy were correlated with SCI variables.

Correlational data analysis described the degree of association between variables. The degree significance of variable association determined whether to reject or fail to reject the study hypotheses. A statistically significant relationship between variables was expressed as $p$ (Suresh \& Chandrashekara, 2012). If the $p$-value is less than or equal to a predetermined level of significance, then the null hypothesis $\left(\mathrm{H}_{0}\right)$ was rejected and the alternative hypothesis $\left(\mathrm{H}_{\mathrm{a}}\right)$ would be supported. In contrast, if the $p$-value is greater than the predetermined level of significance, the null hypothesis would not be rejected, and no support would be claimed for the alternative hypothesis.

\section{RESULTS}

\subsection{Data Cleaning and Dataset Assumptions}

Five hundred forty-three participants responded to the online survey. The process of data cleaning determined that one respondent had eight missing answers, another had 12 missing answers, and 340 participants had 24 missing answers. Respondent surveys with missing answers were removed from the study leaving the sample size at $\mathrm{N}=201$. Two rounds of normality boxplots identified 17 participants with outliers but no multivariate outliers were identified using the Mahalanobis distance test. Given the large sample $(\mathrm{N}=201)$ and the lack of multivariate outliers, these univariate outliers were not deemed to be a problem and those respondent answers were retained in the sample. However, as a precautionary analytical measure against potentially non-normal distributions, both Pearson and Spearman correlations were calculated.

Bivariate normality was examined using bivariate scatterplots; thus, no discernable non-linear patterns in the scatter of data points were evident. Each participant only completed one survey therefore, the independence of errors was not deemed a problem, and the Durbin-Watson statistic for regression model was within normal limits. Multicollinearity was found not to be a problem based on the variance inflation factor (VIF) and tolerance statistics in the regression model. Using probability-probability (P-P) plots and a frequency histogram for the regression residuals, the results showed the variance along the regression line was the same for all values of firm performance, the predictor variable. Also, all regression residual scores were within plus or minus three standard deviations. Taken as a whole, the assumptions for testing results for Pearson correlations and multiple regression analysis were adequate.

\subsection{Demographics}

Table 1 displays the frequency counts for select variables. The largest group of participants worked within the manufacturing industry $(20.9 \%)$ with either the second highest being the distribution $(7.0 \%)$ or energy and utilities $(7.0 \%)$ industry. The most common cultures were clan (29.9\%) or market $(28.9 \%)$.

Table 2 displays the descriptive statistics for the nine aggregated scale scores. The Cronbach alpha reliability coefficients ranged in size from $\mathrm{a}=.65$ to $\mathrm{a}=.88$ with the median sized alpha being a $=0.80$. Only one scale fell below the $a=.70$ threshold (the internal integration scale which was $\mathrm{a}=.65)$. This result suggested that almost all the scales had adequate levels of internal reliability. Cronbach alpha is an index of reliability for the variables being measured. The higher the variable score, the more reliable the scale of measurement. Scores exceeding 0.70 were considered an acceptable reliability coefficient.

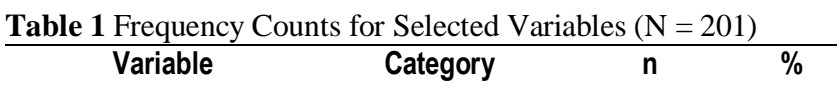

\begin{tabular}{llcc} 
Company Industry & & & \\
& Airline/Aerospace & 11 & 5.50 \\
& Construction & 13 & 6.50 \\
& Distribution & 14 & 7.00 \\
& Food & 11 & 5.50 \\
& Energy \& Utilities & 14 & 7.00 \\
& Manufacturing & 42 & 20.90 \\
& Other & 96 & 47.60 \\
Organizational Grouping & & \\
& & & \\
& Clan & 58 & 28.90 \\
& Adhocracy & 44 & 21.90 \\
& Market & 58 & 28.90 \\
& Hierarchy & 41 & 20.40 \\
\hline
\end{tabular}

\subsection{Research Question Findings}

The first research question asked, "To what extent, if any, does supply chain integration correlate to firm performance?" To test this hypothesis, Table 3 displays both the Pearson and Shearman's Rho correlations for the four integration scales with the firm performance scale. The Spearman correlations were included as a precautionary analytical method due to the presence of some outliers found in the data screening process. Inspection of the table found that the equivalent correlations to be similar in size. In fact, 
for the supplier and total integration scores, the Pearson and Spearman coefficients were identical.

Table 2. Psychometric Characteristics for Aggregated Scale Scores $(N=201)$

\begin{tabular}{lccrrrr}
\hline & $\mathbf{n}$ & $\mathbf{M}$ & SD & Low & High & $\boldsymbol{\alpha}$ \\
\hline Customer Integration & 5 & 3.46 & 0.92 & 1 & 5 & 0.80 \\
Supplier Integration & 7 & 3.46 & 0.86 & 1 & 5 & 0.84 \\
Internal Integration & 5 & 3.84 & 0.76 & 1.4 & 5 & 0.65 \\
Total Integration & 17 & 3.59 & 0.67 & 1.53 & 5 & 0.86 \\
Firm Performance & 5 & 3.74 & 0.73 & 1.2 & 5 & 0.88 \\
Clan Score & 6 & 27.75 & 17.32 & 0 & 100 & 0.86 \\
Adhocracy Score & 6 & 15.77 & 9.38 & 0 & 39.17 & 0.77 \\
Market Score & 6 & 26.98 & 14.80 & 0 & 77.50 & 0.77 \\
Hierarchy Score & 6 & 29.51 & 16.71 & 0 & 89.17 & 0.78 \\
\hline
\end{tabular}

All eight correlations in Table 3 were significant at the $p<.001$ level. Specifically, Customer Integration with firm performance for both the Pearson $(r=.40, p<.001)$ and Spearman Rho's $\left(r_{\mathrm{s}}=.38, p<.001\right)$; Supplier Integration with firm performance for both the Pearson $(r=.36, p<.001)$ and Spearman Rho's $\left(r_{\mathrm{s}}=.36, p<.001\right)$; Internal Integration with firm performance for both the Pearson $(r=.29, p<.001)$ and Spearman Rho's $\left(r_{\mathrm{s}}=.28, p<.001\right)$; and Total Integration with firm performance for both the Pearson $(r=$ $.45, p<.001)$ and Spearman Rho's $\left(r_{\mathrm{s}}=.45, p<.001\right)$. These results provide support to reject the null hypothesis.

Table 3. Pearson and Spearman's Rho Correlations for Integration Scales with Firm Performance Scale $(\mathrm{N}=201)$

\begin{tabular}{lll}
\hline & \multicolumn{2}{c}{ Firm Performance Scale } \\
\hline Integration Scale & Pearson & Spearman's Rho \\
\hline Customer Integration & $0.40^{* * *}$ & $0.38^{* * *}$ \\
Supplier Integration & $0.36^{* * * *}$ & $0.36^{\star * * *}$ \\
Internal Integration & $0.29^{* * * *}$ & $0.28^{* * *}$ \\
Total Integration & $0.45^{* * * *}$ & $0.45^{* * *}$ \\
\hline
\end{tabular}

Note. Both types of correlations are presented as an analytical crosscheck because of non-normality in the dataset. $* * * * p<.001$

The second research question asked, "To what extent, if any, does organizational culture correlate to the relationship between supply chain integration and firm performance?" There were two related hypotheses. The first state, "Adhocracy culture type with greater organizational flexibility will have a greater degree of positive correlation on supply chain integration and firm performance than hierarchy and market culture types identified as low organizational flexibility" and the second stated, "Adhocracy culture type with an external focus will have a greater degree of positive correlation on supply chain integration and firm performance than hierarchy and clan culture types identified as having and internal focus."
Two methods were utilized to answer this question: Table 4 reveals a standard multiple regression model to display the prediction of firm performance based on the total integration score controlling for organizational flexibility and external focus scores. In the second analysis, Table 5 displays the Spearman correlations used to compare the total integration score with firm performance based on eight organizational culture subsets. In Table 4, the model was statistically significant $(p=.001)$ and accounted for $25.4 \%$ of the variance in the dependent variable. Specifically, greater firm performance was positively related to a: (a) greater flexibility score $(\beta=.22, p=.001)$; (b) greater external focus $(\beta=.16, p=.01)$; and (c) greater total integration score $(\beta=.39, p=.001)$.

Table 4. Prediction of Firm Performance Based on Total Supply Chain Integration Controlling for Organizational Culture Scores. Standard Multiple Regression ( $\mathrm{N}=201)$

\begin{tabular}{lllll}
\hline Scale & $\mathbf{B}$ & $\mathbf{S E}$ & $\boldsymbol{\beta}$ & $\mathbf{p}$ \\
\hline Intercept & 1.58 & 0.27 & & 0.001 \\
Flexibility Score & 0.02 & 0.00 & 0.22 & 0.001 \\
External Focus Score & 0.01 & 0.01 & 0.16 & 0.01 \\
Total Integration & 0.42 & 0.07 & 0.39 & 0.001 \\
\hline
\end{tabular}

Note. Durbin-Watson statistic: 2.13 Full Model: $F(3,197)=22.39$, $p=.001 . R^{2}=.254$.

In Table 5, for the entire sample $(N=201)$, the Spearman correlation between total integration and firm performance was significant $\left(r_{\mathrm{s}}=.45, p<.001\right)$. The related coefficient of determination $\left(r_{\mathrm{s}}^{2}\right)$ accounted for $20.3 \%$ of the shared variance between the two variables. Among the eight organizational culture subsets, the shared variance between total integration and firm performance was highest in the 58 clan organizations $\left(r_{\mathrm{s}}=.52, p<.001,27.0 \%\right.$ shared variance) and lowest in the 41 hierarchical organizations $\left(r_{\mathrm{s}}=.34, p<\right.$ $.05,11.6 \%$ shared variance).

\subsection{Discussion}

The results in Table 4 suggested an organization that is flexible and has an external focus does indeed have a greater positive correlation on total integration and firm performance. According to Cameron and Quinn (2011) this would suggest an adhocracy culture. However, Table 5 results suggested a clan organizational type has the greatest positive correlation on total integration and firm performance. The seeming dichotomy in culture type as shown in Table 4 and Table 5 results, as defined by the CVF, (Cameron \& Quinn, 2011) states that the clan culture type is flexible but internally focused whereas the adhocracy culture type is both flexible and externally focused.

To explain this dual-culture dichotomy, Braunscheidel et al., (2010), Cameron and Quinn (2011), and Ramsey (2014), suggested that organizations are a combination of multiple sub-cultures. A plausible explanation for the dualculture outcome was sub-cultures might be confounding the results. One of the assumptions underlying the CVF model used in this study was that an organization might exhibit a combination of culture types. Previous research confirmed the organizational predominance of sub-cultures (Cameron \& Quinn, 2011; Ramsey, 2014). 
Table 5. Spearman Correlations for Total Integration with Firm Performance Based on Selected Organizational Culture Subsets of the Dataset

\begin{tabular}{lllll}
\hline & & & & $\begin{array}{l}\text { Expressed } \\
\text { as a \% }\end{array}$ \\
\hline Organizational Culture Subset & $\mathrm{n}$ & $\mathrm{r}_{\mathrm{s}}$ & & $\mathrm{rs}_{\mathrm{s}}{ }^{2}$ \\
\hline Entire Combined Sample & 201 & 0.45 & $* * * *$ & 20.3 \\
Stability / Control Only & 99 & 0.40 & $* * * *$ & 16.0 \\
Flexibility / Discretion Only & 102 & 0.47 & $* * * *$ & 22.1 \\
Internal / Integration Only & 99 & 0.48 & $* * * *$ & 23.0 \\
External / Differentiation Only & 105 & 0.39 & $* * * *$ & 15.2 \\
Clan Only & 58 & 0.52 & $* * * *$ & 27.0 \\
Adhocracy Only & 44 & 0.36 & $*$ & 13.0 \\
Market Only & 58 & 0.39 & $* * *$ & 15.2 \\
Hierarchy Only & 41 & 0.34 & $*$ & 11.6 \\
\hline
\end{tabular}

Note. Each coefficient is the Spearman correlation between the Total Integration Score and the Firm Performance Score including only those participants from that particular organizational culture. $* p<.05$. *** $p<.005$. **** $p<.001$

Furthermore, Quinn and Rohrbaugh (1983) maintained organizations may perform better with more than one culture type because they can capitalize on the strengths of each culture. The 58 clan survey participants may have been in a clan sub-culture when answering the OCAI forced ranking questions, yet when answering the question of corporate integration strategies, the culture type supported adhocracy. Taken as a whole, the survey results provided support to reject the null hypothesis.

Another possible explanation of the dual culture result was organizational flexibility, which is present in both adhocracy and clan cultures, is more significant to SCI and improved performance than an internal or external focus. This finding was consistent with other organizational flexibility theorists who maintained the highly disruptive contemporary business environment requires organizational flexibility in order to respond quickly to changing demands (Jayant \& Ghagra, 2013; Singh \& Acharya, 2013).

This research study examined the relationships between organizational culture, SCI, and firm performance. The results of this study provided evidence to support a link between SCI and firm performance as mediated by organizational culture. Furthermore, the evidence to support organizational culture, as measured by the competing values framework (CVF), did affect the ability of firms to integrate customer and supplier practices.

Regarding the three integration variables, the results showed that customer, supplier, and internal, when present, increased firm performance. The important point was relationships must extend beyond the dyadic level of buyer and customer or buyer and supplier to include all entities within the supply chain. This builds upon the assertions of Mackerprang et al. (2014) who stated the confusing terminology and focus on fragmented and binary relationships prevents successful SCI.

\section{CONCLUSIONS}

The general problem that precipitated the need for this study was the lack of consistent research findings and the limited empirical evidence in SCI literature, which makes it difficult for supply chain leaders to design and implement practical integration solutions. Inter-firm business processes and integration initiatives require organizational alignment to minimize overall costs and maximize firm performance (Braunscheidel et al., 2010; Cao et al., 2015). Organizational alignment necessitates major changes in organizational culture and mindset among supply chain members (Braunscheidel et al., 2010; Cao et al., 2015). The specific problem is how to identify organizational culture types that are most applicable for supply chain integration initiatives and increased firm performance.

An unexpected result of this study was that both the adhocracy and clan cultures positively influenced supply chain integration and firm performance. Both the standard multiple regression and the Spearman correlation models were used to test an organization's culture impact on SCI and firm performance. The findings suggested organizations with a dual culture, such as adhocracy and clan, do significantly influence SCI and firm performance. The findings for this study were consistent with Cao et al. (2015) who found that the development (adhocracy) culture and group (clan) culture were significant contributors to customer, supplier, and internal integration, whereas the hierarchical culture negatively influenced both internal integration and customer integration.

\subsection{Limitations}

Several limitations were considered when interpreting the results. The population consisted of supply chain professionals and procurement specialists located in companies within the United States. Expanding the context to foreign countries such as China, the results may help to reduce global integration barriers. In the last few decades, western countries outsourced a large amount of manufacturing to China (Flynn et al., 2010). National and organizational culture plays a critical role in developing relationships across borders. Further research initiatives could benefit from examining cross-cultural differences between SCI and firm performance.

Organizational culture was considered as one variable in this study. Researchers suggested there are many subcultures that exist within one organizational culture (Braunscheidel et al., 2010; Cameron \& Quinn, 2011; Ramsey, 2014). Palthe and Kossek (2003) argued that subcultures could enable or hinder implementation of an organization's strategic initiatives. In this case, perhaps the presence or absence of sub-cultures could affect the implementation of supply chain initiatives and firm performance.

An interesting study for future research would be to compare the presence of sub-cultures and their influence on SCI programs. This study suggested two cultures, namely adhocracy and clan, provided evidence to support increases in SCI success. However, the study aggregated culture at the organizational level and did not delve into the sub-culture behaviors and links between SCI and firm performance. Future studies could examine the differing behavior elements of sub-cultures and their influence on SCI efforts. 
Further research is needed which gives deeper insights into what constitutes organizational flexibility and the impact on SCI capabilities. For example, can internal organizational flexibility from a culture perspective meet the numerous SCI demands or can an organization excel in one component of flexibility, such as technology flexibility, and still be successful in supporting SCI initiatives. In addition, does organizational flexibility, as represented in the clan and adhocracy cultures, influence SCI and firm performance more than having an internal or external focus? Empirical research in this area could enrich the organizational, supply chain, and flexibility literature.

\subsection{Implications}

Most empirical SCI studies focused on the dyadic relationship between buyer and seller. Incorporating customer, supplier, and internal factors into the SCI model adds greater depth to the SCI literature. The main theoretical contribution was introducing organizational culture as key dimension influencing SCI and greater firm performance. The results from this study established a direct link between organizational culture and increased SCI. Using organizational culture as the antecedent to SCI practices, this study provided another explanation as to why some supply chain integration efforts are effective while others are not. The findings provided support that SCI and firm performance increased in an adhocracy and clan culture.

Despite significant efforts, it still is difficult to integrate processes and practices across organizational boundaries. There continues to be reluctance to change and a lack of sharing, collaboration, and relationship development among trading partners. Developing relational capabilities between organizations is a gradual process to improve firm performance and competitive position in the marketplace. Frequent communication and relationship development among firms leads to shared values, inter-organizational teams, knowledge transfer, and exchange of information. When positive relationship dynamics between firms are absent, SCI efforts are more likely to fail.

Moving from SCI theory to practice was difficult for most organizations as there was not a set of definitions, dimensions, and integration succession plans. However, if efforts to integrate externally with other trading partners are unsuccessful, the organization's culture may be a contributor. Therefore, culture change efforts must be addressed to bring integration practices into alignment with supply chain partners. Although the study findings indicated that organizational culture does play a significant role in SCI and firm performance, changing culture characteristics is not an easy task to accomplish. In addition, any single culture type in and of itself is not totally responsible for improved SCI.

Governance research identified organizational and relationship flexibility as a contributing factor to successful supply chain performance (Bitran et al., 2007). Given the turbulent economic environment, organizations' ability to adapt in a flexible manner to upstream and downstream changes depended on relationship governance practices. The results of this study indicated that organizational flexibility found in the clan and adhocracy cultures, did positively influence supply chain integration. Furthermore, the theoretical underpinnings of this study, based on the relational theory, found evidence that supports the importance of supply chain relationship development among all trading partners. Clan and adhocracy culture types that promote flexibility in downstream and upstream relationship governance practices had a better chance of integration success.

\subsection{Study Summary}

The rapidly changing business environments presented a multitude of uncertainties for organizational leaders to sustain a competitive advantage on their own, prompting leaders to look beyond traditional boundaries (Wang et al., 2018). Over the last decade SCI became a key factor in achieving organizational improvements and creating sustainable competitive advantage. However, the shift from autonomous organizations acting alone to an integrated supply chain of information sharing and collaboration among multiple trading partners was a complex transformation (deSouza \& Haddud, 2017). In fact, only $10 \%$ of worldwide supply chains are successfully integrated (Msimangira \& Venkatraman, 2014). Particularly challenging was integration among channel partners required change; a new organizational leader mindset accompanied by inter-firm relationship development practices. Organizational and behavioral barriers within the supply chain are a major detriment to SCI performance.

Study results highlighted the importance of a flexible organizational structure, as shown in the clan and adhocracy cultures, increased SCI and firm performance. As competitive forces intensified, the need for firms to develop a flexible organizational structure to leverage SCI practices will increase. The research results are meant to provide more insights into increasing SCI efforts and improved firm performance through flexible culture alignment. More rather than less integration benefits the chances of organizational survival in the foreseeable future.

\section{ACKNOWLEDGEMENTS}

The author thanks the Center for Educational and Instructional Technology Research, School of Advanced Studies, University of Phoenix, for supporting the preparation of this article.

\section{REFERENCES}

Barratt, M. (2004). Understanding the meaning of collaboration in the supply chain. Supply Chain Management: An International Journal, 9(1), pp. 30-42.

Braunscheidel, M. J., Suresh, N. C., \& Boisnier, A. D. (2010). Investigating the impact of organization culture on supply chain integration. Human Resource Management, 49(5), pp. 883-911.

Bitran, G. R., Gurumurthi, S., \& Sam, S. L. (2007). The need for third-party coordination in supply chain governance. MIT Sloan Management Review, 48(3), pp. 30-37.

Cadden, T., Marshall, D., \& Cao, G. (2013). Opposites attract: Organizational culture and supply chain performance. Supply Chain Management: An International Journal, 18(1), pp. 86103.

Cameron, K., \& Quinn, R. (2011). Diagnosing Changing Organizational Culture: Based on the Competing Values Framework (3rd ed.). Hoboken, NJ: Jossey-Bass A Wiley Imprint.

Cao, Z., Huo, B., Li, Y., \& Zhao, X. (2015). The impact of 
organizational culture on supply chain integration: A contingency and configuration approach. Supply Chain Management: An International Journal, 20(1), pp. 24-41.

Chen, H., Mattioda, D. D., \& Daugherty, P. J. (2007). Firm-wide integration and firm performance. The International Journal of Logistics Management, 18(1), pp. 5-21.

Childerhouse, P., \& Towill, D. R. (2011, December 15). Arcs of supply chain integration. International Journal of Production Research, 49(24), pp. 7441-7468.

Christopher, M. (Ed.). (1982). Supply chain management: Logistics catches up with strategy. Logistics: The Strategic Issues (pp. 63-75).

Closs, D. J., \& Savitskie, K. (2003). Internal and external logistics information technology integration. The International Journal of Logistics Management, 14(1), pp. 63-76.

Danese, P., \& Ramano, P. (2011). Supply chain integration and efficiency performance: A study on the interactions between customer and supplier integration. Supply Chain Management: An International Journal, 16(4), pp. 220-230.

Delbufalo, E. (2012). Outcome of inter-organizational trust in supply chain relationships: A systematic literature review and meta-analysis of the empirical evidence. Supply Chain Management: An International Journal, 17(4), pp. 377-402.

deSouza, A., Haddud, A. (2017). Supply chain management integration in maintenance and repair services. Operations and Supply Chain Management, 10(4), pp. 200-213.

Ellram, L. M., \& Cooper, M. C. (2014, January). Supply chain management: It's all about the journey, not the destination. Supply Chain Management, 50(1), pp. 8-20.

Fawcett, S. E., \& Magnan, G. M. (2002). The rhetoric and reality of supply chain integration. International Journal of Physical Distribution \& Logistics Management, 32(5), pp. 339-361.

Fawcett, S. E., Magnan, G. N., \& McCarter, M. W. (2008). Benefits, barriers, and bridges to effective supply chain management. Supply Chain Management: An International Journal, 13(1), pp. 35-48.

Feng, T., Li, T., Sun, L., \& Wong, D. (2013). External involvement and operational performance: The mediating role of internal integration. Chinese Management Studies, 7(3), pp. 488-507.

Flynn, B. B., Huo, B., \& Zhao, X. (2010). The impact of supply chain integration on performance: A contingency and configuration approach. Journal of Operations Management, 28, pp. 58-71.

Harrigan, K. R. (1984). Formulating vertical integration strategies. Academy of Management Review, 9(4), pp. 638-652.

Hartnell, C. A., Ou, A. Y., \& Kinicki, A. (2011). Organizational culture and organizational effectiveness: A meta-analytic investigation of the competing values framework's theoretical suppositions. Journal of Applied Psychology, 96(4), pp. 677-694.

Huo, B. (2012). The impact of supply chain integration on company performance: An organizational capability perspective. Supply Chain Management: An International Journal, 117(6), pp. 596-610.

Huo, B., Qi, Y., Wang, Z., \& Zhao, X. (2014). The impact of supply chain integration on firm performance. Supply Chain Management: An International Journal, 19(4), pp. 369-384.

Jayant, A., \& Ghagra, H. S. (2013, March). Supply chain flexibility configurations: Perspectives, empirical studies and research directions. International Journal of Supply Chain Management, 2(1), pp. 21-29.

Johnson, P., Shafiq, A., Awaysheh, A., \& Leenders, M. (2014). Supply organizations in North America: A 24 year perspective on roles and responsibilities 1987-2011. Journal of Purchasing and Supply Management, 20, pp. 130-141.

Kim, D., \& Lee, R. P. (2010). Systems collaboration and strategic collaboration: Their impacts on supply chain responsiveness and market performance. Decisions Sciences, 41(4), pp. 955981.

Kim, D. (2013). Relationship between supply chain integration and performance. Operational Management Resources, 6, pp. 7490.

Leuschner, R., Rogers, D., \& Charvet, F. (2013, Apr). A metaanalysis of supply chain integration and firm performance. Journal of Supply Chain Management, 49(2), pp. 34-57.

Mackelprang, A. W., Robinson, J. L., Bernades, E., \& Web, G. S. (2014). The relationship between strategic supply chain integration and performance: A meta-analytic evaluation and implications for supply chain management research. Journal of Business Logistics, 35(1), pp. 71-96.

Mellat-Parast, M. (2013). Supply chain quality management: An inter-organizational learning perspective. International Journal of Quality \& Reliability Management, 30(5), pp. 511529.

Mello, J., \& Stank, T. (2005). Linking firm culture and orientation to supply chain success. International Journal of Physical Distribution \& Logistics Management, 35(8), pp. 542-554.

Mentzer, J. T., DeWitt, W., Keebler, J., Min, S., Nix, N. W., Smith, C. D., \& Zacharia, Z. G. (2001). Defining supply chain management. Journal of Business Logistics, 22(2), pp. 1-25.

Msimangira, K., \& Venkatraman, S. (2014). Supply chain management integration: Critical problems and solutions. Operations and Supply Chain Management, 7(1), pp. 23-31.

Narasimhan, R., Swink, M., \& Viswanathan, S. (2010). On decisions for integration implementation: an examination of complementarities between product-process technology integration and supply chain integration. Decision Sciences, 41(2), pp. 355-372.

Palthe, J., \& Kossek, E. (2003). Subcultures and employment modes: Translating HR strategy into practice. Journal of Organizational Change Management, 16(3), pp. 287-308.

Patnayakuni, R., Rai, A., \& Seth, N. (2006). Relational antecedents of information flow integration for supply chain coordination. Journal of Information Systems, 23(1), pp. 13-49.

Quinn, R. E., \& Rohrbaugh, J. (1983, Mar). A spatial model of effectiveness criteria: Towards a competing values approach to organizational analysis. Management Science, 29(3), pp. 363-377.

Ramsey, T. (2014). Organizational culture impact on service supply chain integration in corporate lodging programs (Doctoral dissertation).

Sambasivan, M., \& Yen, C. (2010). Strategic alliances in a manufacturing supply chain. International Journal of Physical Distribution \& Logistics Management, 40(6), pp. 456-474.

Schoenikherr, T., \& Swink, M. (2012). Revisiting the arcs of integration: Cross-validations and extensions. Journal of Operations Management, 30, pp. 99-115.

Singh, R. K., \& Acharya, P. (2013, September). Supply chain flexibility: A framework of research dimensions. Global Journal of Flexible Systems Management, 14(3), pp. 157-166.

Suresh, K. P., \& Chandrashekara, S. (2012, Jan-Apr). Sample size estimation and power analysis for clinical research studies. Journal of Human Reproductive Sciences, 5(1), pp. 7-13.

Tong, Y. K., \& Arvey, R. D. (2015). Managing complexity via the competing values framework. Journal of Management Development, 34(6), pp. 653-673.

Udin, Z., Mohtar, S., \& Othman, A. (2008). Collaborative supply chain managements: The hybrid knowledge-based development approach to suppliers-customers perspective. Operations and Supply Chain Management, 1(2), pp. 130141.

Vijayasarathy, L. R. (2010). Supply integration: An investigation of its multidimensionality and relational antecedents. International Journal of Production Economics, 124, pp. 489-505.

Wang, M., Jie, F., \& Abareshi, A. (2018). Logistics capability, supply chain uncertainty and risk, and logistics performance: An empirical analysis of Australian courier industry. Operations and Supply Chain Management, 11(1), pp. 45-54 
Whitfield, G. and Landeros, R. (2006). Supplier Diversity Effectiveness: Does Organizational Culture Really Matter? Journal of Supply Chain Management, 42, pp. 16-28.

Zhao, X., Huo, B., Selen, W., \& Yeung, J. H. (2011). The impact of internal integration and relationship commitment on external integration. Journal of Operations Management, 29(1-2), pp. 17-32.

Dr. Mary G. Porter is the owner and CEO of Emergent Safety Supply located in Illinois. Emergent Safety Supply is a certified women-owned business and national distributor of safety and janitorial supplies. She received her Ph.D. in Operational Design and Leadership from University of Phoenix and her BA and MS from DePaul University, Chicago. Her research interests are in supply chain management, supply chain integration and distribution. 